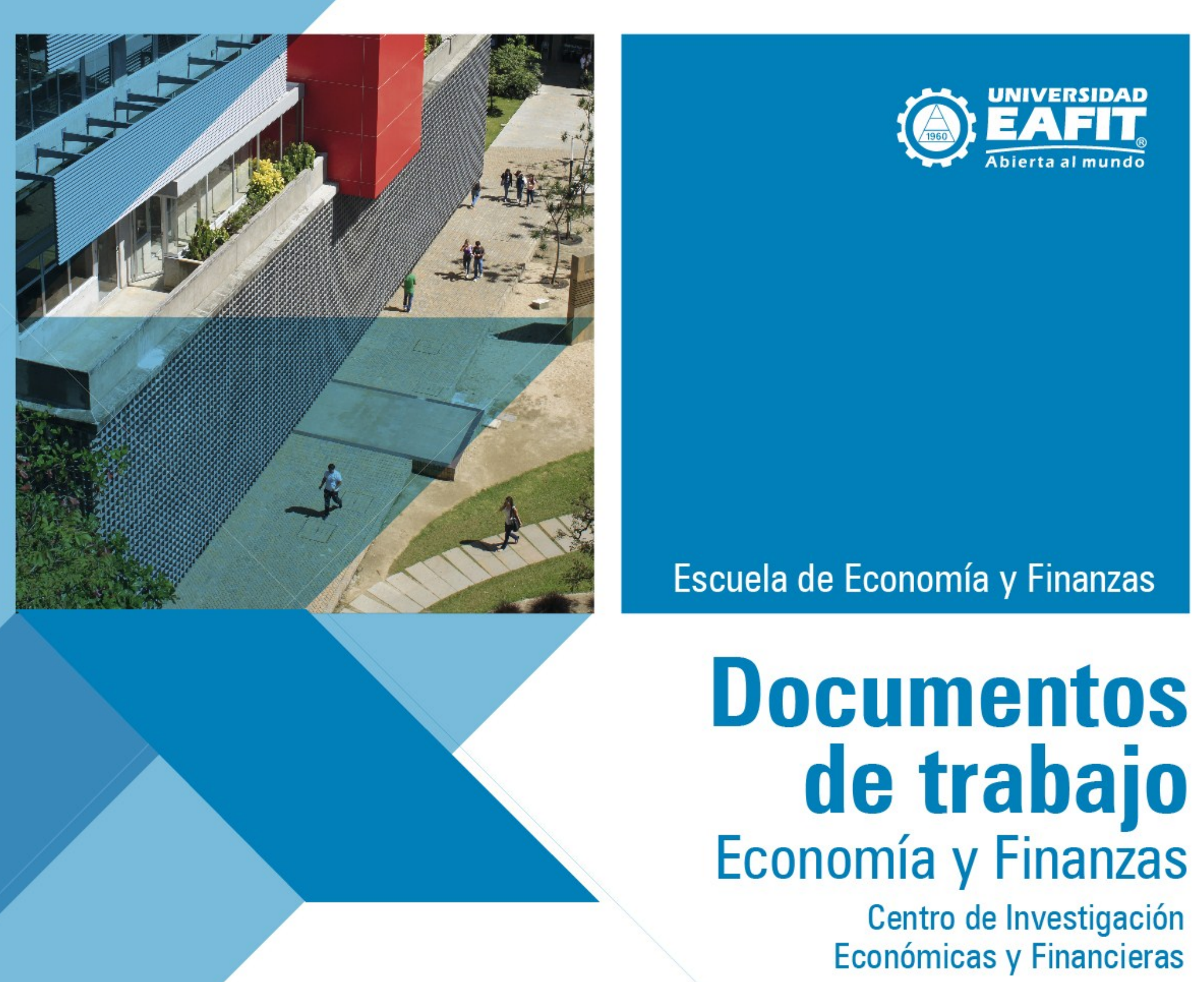

No. 16-28 Happiness and victimization In Latin America

2016 Carolina Ortega Londoño, Daniel Gómez Mesa, Lina CardonaSosa, Catalina Gómez Toro

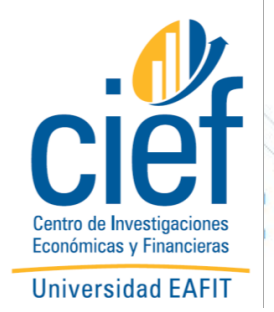




\title{
HAPPINESS AND VICTIMIZATION IN LATIN AMERICA
}

\author{
Carolina Ortega Londoño \\ Daniel Gómez Mesa \\ Lina Cardona-Sosa \\ Universidad EAFIT \\ Banco de la República de \\ Catalina Gómez Toro * \\ Universidad EAFIT \\ Colombia \\ Universidad EAFIT
}

\begin{abstract}
In recent decades, studies on economics have identified happiness as a life quality indicator that not only accounts for individuals' socioeconomic improvement but also accounts for their interactions with institutions and public goods, such as personal safety and protection of life. This study examines the determinants of individual happiness of Latin American citizens by focusing on whether the individual had been a victim of a crime in the last twelve months. To do this, a generalized ordered logit with partial constraints is used to analyze data obtained from the Americas Barometer Survey of 2014. The individual selfreported level of life satisfaction is used to study its relationship with having been a victim of a crime during the previous year. The results suggest the existence of a negative relationship between having been a victim of a crime in the past twelve months and being very satisfied with life.
\end{abstract}

JEL Code: I3, K42, D62

Key Words: crime, happiness, life satisfaction, generalized ordered logit.

\section{INTRODUCTION}

The measurement of happiness is a topic that continues to attract the attention of economists. As Helliwell, Huang, and Wang (2015) state in the World Happiness Report 2015, happiness, understood as an individual's subjective well-being, is considered an indicator of social progress.

This claim, however, gives rise to the question, "How do economic variables such as economic growth, inflation, unemployment, etc. affect each person's well-being?" If wellbeing is related to happiness, understanding its determinants could improve policy makers' knowledge regarding how their decisions within the institutional context might eventually affect the social welfare of the population. Understanding the relationship between economic variables and happiness could allow economists and policy makers to empirically

\footnotetext{
* Corresponding author. Carrera 49 \# 7 sur -50, Medellín, Colombia; e-mail: cgomezt1@eafit.edu.co

${ }^{\dagger}$ E-mail: 1cardoso@banrep.gov.co. The contents of this work do not reflect the opinion of Banco de la República or its Board of Directors. Any mistake is authors' responsibility only.
} 
contrast theories, such as the consumption-leisure model, and understand the importance of individual income when defining subjective well-being (Frey \& Stutzer, 2002).

For many decades, there has been a generalized focus of policy makers on raising income under the hypothesis that this is the way to improve social welfare. However, studies such as that by Easterlin (2004), find no empirical evidence to support this hypothesis, but rather, they find that income is not the only determinant of individual subjective well-being. As Frey and Stutzer (2002) find, even though countries such as the United States, Belgium and Japan have experienced substantial GDP per capita growth, this positive trend has not translated to higher levels of life satisfaction. Moreover, the study considers the importance of other variables, such as past experiences, sickness, marriage, divorce, etc., when explaining individual life satisfaction.

Accordingly, the literature recognizes additional determinants of individual life satisfaction, i.e., individual safety, crime, etc. According to Powdthavee (2005), having been the victim of a crime reduces the individual's level of well-being. Therefore, the study of the effects of crime is particularly relevant in regions such as Africa and Latin America given that Latin America as a region has the second highest rate of victimization, being outranked only by sub-Saharan Africa (Di Tella, MacCulloch, \& Ñopo, 2008), a situation that is acknowledged by the citizens of the Latin American countries.

Based on a sample of 29,485 individuals who participated in the LAPOP survey that was administered to Latin-Americans, Figure 1 reports the frequency of each possible answer given to the question, "In your opinion, what is the most serious problem facing this country?" The most frequent answer was delinquency and crime at $23 \%$, whereas $5 \%$ indicated lack of security and 3\% believed it was violence. The second greatest issue, as reported by $15 \%$ of the respondents, was concern about the economic situation. These results indicate that crime and a lack of individual safety are significant contributing factors to the negative perceptions of Latin American countries.

The extent to which victimization from any crime is related to life satisfaction in Latin America has yet to be explored. Accordingly, the objective of this study is to identify and quantify the effect of having been a victim of crime in the past 12 months on the level of life satisfaction as reported by Latin-American citizens in 2014. We use data from the LAPOP AmericasBarometer Survey of 2014. Our empirical approach is based on a generalized ordered logit, which is a robust alternative to the approaches used in previous studies that have found a relationship between self-reported life satisfaction and crime. The results suggest that having been a victim of a crime in the last 12 months diminishes the probability of an individual reporting the highest level of life satisfaction in each of the countries considered. The main contributions of this study are threefold. First, we provide new evidence regarding the relationship between victimization from crime and life satisfaction using an extended survey administered in the majority of the Latin American countries, a region with a long history of violence. Second, we employ a robust technique to overcome econometric problems faced by past studies, and third, we identify heterogeneous effects of crime for each of the countries analyzed. 


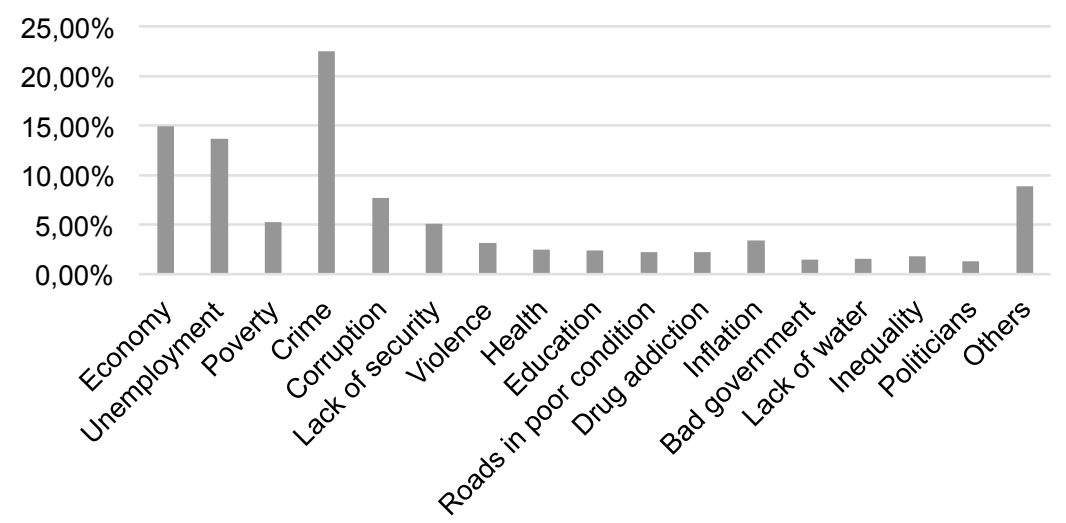

Figure 1: Average answer to the question: What is the most serious problem facing this country?

Source: Authors' calculations based on LAPOP 2014.

This paper is organized as follows. Section II presents a review of the main studies on individual life satisfaction and its relationship with crime and victimization. In section III, we describe the data used for the analysis, and we discuss the empirical approach employed in section IV. In section $\mathrm{V}$, the main empirical findings are reported, and section VI concludes the paper.

\section{LITERATURE REVIEW}

Happiness has been a topic of interest since Aristotle defined it as the ultimate goal in life in his work Nichomacean Ethics. Later, classic economists redirected their efforts to gain a better understanding of wealth. The founder of utilitarianism, Jeremy Bentham, proposed a happiness measurement that accounts for both the pleasures and the pains experienced by the human being. However, the economists of the time chose to study the individual's utility from an ordinal approach. Eventually, classic economists would provide the setting to develop a theory of rational choice with a limited analysis regarding welfare (Rojas, 2009).

The absence of a quantitative measure of welfare or happiness left the study of happiness to philosophers who proposed some guidelines under which anyone could determine someone else's well-being without the need to corroborate it. Later, sociologists and psychologists approached the study of happiness through a more scientific method with a focus on subjective well-being such that the level of happiness or well-being was reported directly by the individual (Rojas, 2009).

Economists' interest in the study of happiness began to unfold near the end of the twentieth century, further sustaining the subjective well-being approach. Moses Ambramovitz, in 1959, supported the economists' conviction that economic growth was bounded to welfare growth (Easterlin, 1974), but it was Richard A. Easterlin who, in 1974, was the first to 
study the relationship between happiness and income. Using the results of Gallup surveys from 1946 to 1970 and including 19 countries from different regions around the world, Easterlin found a positive and significant relationship between income and the country's reported level of happiness, although admittedly, in some cases, there was a weak pattern of causality (Easterlin, 1974). The author concluded that even though considerable increases in income per capita were observed, the levels of happiness seemed to be generally stationary. Hence, his conclusion is known as Easterlin's Paradox (Di Tella \& MacCulloch, 2008).

More recently, Easterlin (2004), using data from Europe and America, found that the critical factor was relative wealth in contrast to absolute wealth, suggesting that what matters is one's personal income in comparison to that of others.

Thus, in the last decade, studies have emphasized the explanatory power of non-economic variables when discussing individual well-being. For example, Becchetti (2011) found evidence that individuals are not absolutely homo economicus. His study highlights that various behaviors, such as volunteering, donating and paying price premiums on some products because it is ethically correct, provide evidence that individuals are not totally mercenary. In this sense, he challenges the reductionist model, which classifies people as economical beings and corporations as purely lucrative entities. He further contends that an approach such as the reductionist model limits economic and social advancements (Becchetti, Bruni, \& Zamagni, 2015). Moreover, Becchetti (2011) highlights the importance of relational goods and the lack of analysis of such goods in the literature. Thus, alternative studies that focus on a civil economy with the traditional concept of happiness as a monetary aggregate and that propose to include other non-monetary variables as determinants of happiness are critical (Ansa Eceiza, 2005).

Furthermore, there are numerous studies that analyze happiness and its relationship with macroeconomic variables. Di Tella, MacCulloch, and Oswald (2003), who connect happiness with unemployment and GDP, employ an empirical approach based on an ordered probit with fixed effects using data from Europe and the United States. The authors show that movements of macro variables highly impact life satisfaction. Furthermore, GDP growth is found to be positively related with life satisfaction, and unemployment is determined to be negatively related. Nevertheless, the positive effect of increased income eventually vanishes according to evidence that indicates agents become accustomed to their new levels of income.

Employing the same empirical approach, Cohen (2008), using data from the U.S. General Social Survey (GSS) for the period 1993 to 2004, examines the effects of crime on selfreported levels of life satisfaction. In addition to sociodemographic variables, such as gender, age, occupation and marital status, the study also includes the individual's status with respect to being a victim of a robbery or burglary as a determinant of life satisfaction. He finds a significant and negative effect of household perception of security on self- 
reported levels of life satisfaction. Moreover, the study finds that the most important measure of crime to explain life satisfaction is victimization.

Using data from the Swiss Crime Survey (SCS) for 2011, Staubli, Killias, and Frey (2014) estimate the effect of different crimes on subjective well-being. Using an OLS approach, the study found significant negative effects of victimization on life satisfaction. The effects were more significant when the crimes were directed specifically against the individual, such as sexual offenses. At the same time, the researchers observed a high correlation between life satisfaction and the individual's perception of security as measured by how safe the person feels when walking alone in their neighborhood after dark.

Studying the relation between security and crime variables with life satisfaction is especially relevant in regions such as Africa and Latin America due to the high incidence of victimization experienced by the residents of these regions. Using data for Latin America and the Caribbean obtained from the Gallup World Poll (2006 to 2007), Di Tella, MacCulloch and Nopo (2008) find that Latin America has the second highest rate of reported victimization, preceded only by sub-Saharan Africa. Approximately one out of six Latin-Americans surveyed reported having been robbed in the last 12 months. Their study analyzes crime patterns within different groups and regions around the world. Furthermore, they relate these patterns with emotional factors to determine the real cost of crime and victimization and find that the effect of being victimized exceeds even that of unemployment.

Powdthavee (2005), in a similar study in South Africa, also finds a negative relationship between being a victim of crime and life satisfaction. Moreover, he claims that if a household is located in a high crime area, the effect of being a victim on the level of life satisfaction is negligible as the individual becomes indifferent.

With respect to Colombia, Medina and Tamayo (2012) study the relationship between crime and life satisfaction using data from Medellin, a city with a long history of violence. The main findings suggest that homicide rates, perceptions of neighborhood security and victimization due to a felony (especially robbery) have a negative effect on self-reported life satisfaction. Wills-Herrera, Orozco, Forero-Pineda, Pardo, and Andonova (2011) reported similar conclusions regarding Colombia using different data sources.

Following previous literature, there is some latitude when studying the relationship between crime and life satisfaction for each of the Latin American countries in a disaggregate manner, such as the one we have proposed, and when using a homogenized source of data to define an individual's subjective well-being. 


\section{DATA}

\section{a. LAPOP}

The data used in this study are obtained from the AmericasBarometer, a survey created by the Latin America Public Opinion Project (LAPOP). This survey has been administered annually in Latin American countries since 2000. This is the only free access survey of public opinion and social behavior that meets scientific standards (Vanderbilt University, 2016). The 2014 round of the survey emphasized questions related to crime and violence in each country (Zechmeister, 2014). This study focuses on a 2014 sample to account for a representative sample of the entire region, i.e., Argentina, Bolivia, Brazil, Chile, Colombia, Costa Rica, the Dominican Republic, Ecuador, El Salvador, Guatemala, Haiti, Honduras, Mexico, Nicaragua, Panama, Paraguay, Peru, Uruguay and Venezuela.

\section{b. Measurement of Life Satisfaction}

It is important to first establish a definition of the main variable of interest, namely, life satisfaction, which is assessed using a measure of subjective well-being. According to Kahneman and Krueger (2006), though some care must be taken, this measurement is useful. The authors explain that life satisfaction is not a verifiable or known fact. It is rather "a global retrospective judgment [...] and is determined in part by the respondent's current mood and memory, and by the immediate context" (Kahneman \& Krueger, 2006). Regarding the first issue, the authors consider that, on average, if the surveyed sample is representative of the population, the idiosyncratic effects of recent events are not significant. This suggests that for the present study this issue has already been addressed and is not relevant.

Additionally, because people use past experiences when making future decisions, selfreported life satisfaction provides a good measurement of subjective well-being. Furthermore, reported satisfaction may also be biased due to earlier questions in the survey. The present study lacks such bias because the question of life satisfaction is the second question in the survey, preceded only by the question asking for the individual's year of birth.

\section{c. Descriptive Statistics}

The countries included in this study, as presented in Table 1, are those for which the 2014 LAPOP survey was available ${ }^{1}$. The total sample includes 30,386 individuals. Approximately $5 \%$ of the sample corresponds to each country listed below, with the exception of Bolivia, which accounts for approximately $10 \%$ of the sample. ${ }^{2}$

\footnotetext{
${ }^{1}$ These data were supplied by the Latin American Public Opinion Project at Vanderbilt University, which takes no responsibility for any interpretation of the data.

${ }^{2}$ The countries where selected based primarily on the availability of the survey, but countries such as the United States, Canada, Jamaica and the Guianas were omitted because they are not considered representative of the Latin American region.
} 
Table 1: Sample taken from LAPOP 2014 by country

\begin{tabular}{lrr|lrc}
\hline \multicolumn{1}{c}{ Country } & Frequency & $\mathbf{\%}$ & \multicolumn{1}{c}{ Country } & Frequency & \% \\
\hline \hline México & 1,535 & 5.05 & Peru & 1,500 & 4.94 \\
Guatemala & 1,506 & 4.96 & Paraguay & 1,503 & 4.95 \\
El Salvador & 1,512 & 4.98 & Chile & 1,571 & 5.17 \\
Honduras & 1,561 & 5.14 & Uruguay & 1,512 & 4.98 \\
Nicaragua & 1,546 & 5.09 & Brazil & 1,500 & 4.94 \\
Costa Rica & 1,537 & 5.06 & Venezuela & 1,500 & 4.94 \\
Panamá & 1,508 & 4.96 & Argentina & 1,512 & 4.98 \\
Colombia & 1,496 & 4.92 & Dominican Republic & 1,520 & 5.00 \\
Ecuador & 1,489 & 4.90 & Haiti & 1,512 & 4.98 \\
\cline { 4 - 6 } Bolivia & 3,066 & 10.09 & Total & 30,386 & 100 \\
\hline
\end{tabular}

Source: Authors' calculations based on LAPOP 2014.

Table 2 presents the main descriptive statistics of the variables included in the analysis. Life satisfaction takes the values 1 through 4 , with a mean of 3.28 . Only $2.98 \%$ of the surveyed individuals report being "very dissatisfied" with life (level 1), and 9.32\% report being "somewhat dissatisfied." On the contrary, 44.6\% report being "somewhat satisfied" with life, and $43.1 \%$ report the highest level of satisfaction, "very satisfied."

With respect to sociodemographic variables, $51.6 \%$ of respondents are women; the average age of the participants is 41 years old and have, on average, two children. The average years of education is 9, which corresponds, approximately, to having not completed secondary education, with a standard deviation of 4.5 years, thus highlighting the regions heterogeneity regarding level of education. Moreover, $59 \%$ of the respondents report being married, cohabitating or living in a civil union; $30 \%$ are single; $6 \%$ are separated or divorced and 5\% are widowed. Of the sample, $71 \%$ live in urban areas, and $83 \%$ have access to drinking water in their homes. With respect to employment status, $54.6 \%$ of the sample has a job, and $6 \%$ of the respondents report actively searching for a job, i.e., they are unemployed. Regarding religion, two dummy variables are defined, though they are not mutually exclusive, that indicate whether the individual attends weekly (1) religious meetings or (2) non-religious meetings, and the results find that $32 \%$ attend weekly religious meetings, and $8 \%$ attend non-religious ones.

To define ethnic group in such a varied region, the survey asks the individual to place himself in the category to which he believes he belongs. The results indicate that $46.4 \%$ of the sample consider themselves to be mestizo, the predominant race in Mexico, El Salvador, Honduras, Colombia, Ecuador, Bolivia, Peru, Paraguay and Dominican Republic and $26.8 \%$ consider themselves to be white, the dominant ethnic group in Costa Rica, Uruguay and Argentina. Although only $6.2 \%$ consider themselves to be mulatto, $46 \%$ of the respondents from Brazil consider themselves to be mulatto. Similarly, $10.4 \%$ of all 
respondents classify themselves as indigenous, but $52 \%$ of Guatemalans identify themselves indigenous.

Table 2: Descriptive statistics of variables

\begin{tabular}{|c|c|c|c|c|c|}
\hline Variable & Mean & $\begin{array}{c}\text { Standard } \\
\text { Deviation }\end{array}$ & Variable & Mean & $\begin{array}{l}\text { Standard } \\
\text { Deviation }\end{array}$ \\
\hline $\begin{array}{l}\text { Life } \\
\text { Satisfaction }\end{array}$ & 3.278 & 0.752 & Victim & 0.193 & 0.395 \\
\hline Woman & 0.516 & 0.5 & Neighborhood Safety & & \\
\hline Age & 40.692 & 16.031 & Very unsafe & 0.132 & 0.339 \\
\hline Age Squared & $1,912.84$ & $1,474.99$ & Somewhat unsafe & 0.314 & 0.464 \\
\hline Marital Status & & & Somewhat safe & 0.401 & 0.49 \\
\hline Married & 0.589 & 0.492 & Very safe & 0.147 & 0.355 \\
\hline Single & 0.303 & 0.459 & Attends weekly meetings & & \\
\hline Divorced & 0.059 & 0.236 & Religious & 0.323 & 0.468 \\
\hline Widowed & 0.047 & 0.211 & Non-religious & 0.078 & 0.269 \\
\hline $\begin{array}{l}\text { Education, } \\
\text { years }\end{array}$ & 9.423 & 4.478 & Ethnic Group & & \\
\hline Income & & & White & 0.268 & 0.443 \\
\hline Low & 0.333 & 0.471 & Black & 0.088 & 0.283 \\
\hline Medium & 0.332 & 0.471 & Mestizo & 0.464 & 0.499 \\
\hline High & 0.335 & 0.472 & Mulatto & 0.062 & 0.242 \\
\hline Unemployed & 0.057 & 0.232 & Indigenous & 0.104 & 0.306 \\
\hline $\begin{array}{l}\text { Children, } \\
\text { number }\end{array}$ & 2.223 & 2.193 & Other & 0.013 & 0.114 \\
\hline Urban Area & 0.71 & 0.454 & & & \\
\hline Drinking water & 0.829 & 0.377 & No. Of Observations & \multicolumn{2}{|c|}{30,386} \\
\hline
\end{tabular}

Source: Authors' calculations based on LAPOP 2014.

The income variable is defined qualitatively by three groups, namely, high income, medium income and low income. The LAPOP survey originally divides family (household) income into 16 categories defined by local currency. To have a comparable variable among countries, this study follows the methodology proposed by Di Tella et al. (2003). Individuals' answers are sorted by country, and the individuals are then assigned to one of the three groups such that each category contains approximately $1 / 3$ of the sample for each country. This variable is useful to explain the relationship between income and welfare based on the premise that people care more about relative income than absolute income (Easterlin, 2004). 
Finally, with respect to victimization and security, $19 \%$ of the respondents claim to have been victims of crime in the last 12 months $^{3}$ of whom $48 \%$ are women. Approximately $45 \%$ of the individuals have a sense of safety in their own neighborhoods.

Figure 2 shows the relationship between the percentage of individuals that have been a victim of a crime in the last year and the percentage of individuals who have declared themselves as very satisfied with life in each of the countries considered in the analyses. The figure suggests a negative association: countries with a higher percentage of victimization have lower proportion of individuals reporting the maximum level of life satisfaction.

Figure 2. Percentage of crime victims and proportion of individuals in the maximum level of life satisfaction.

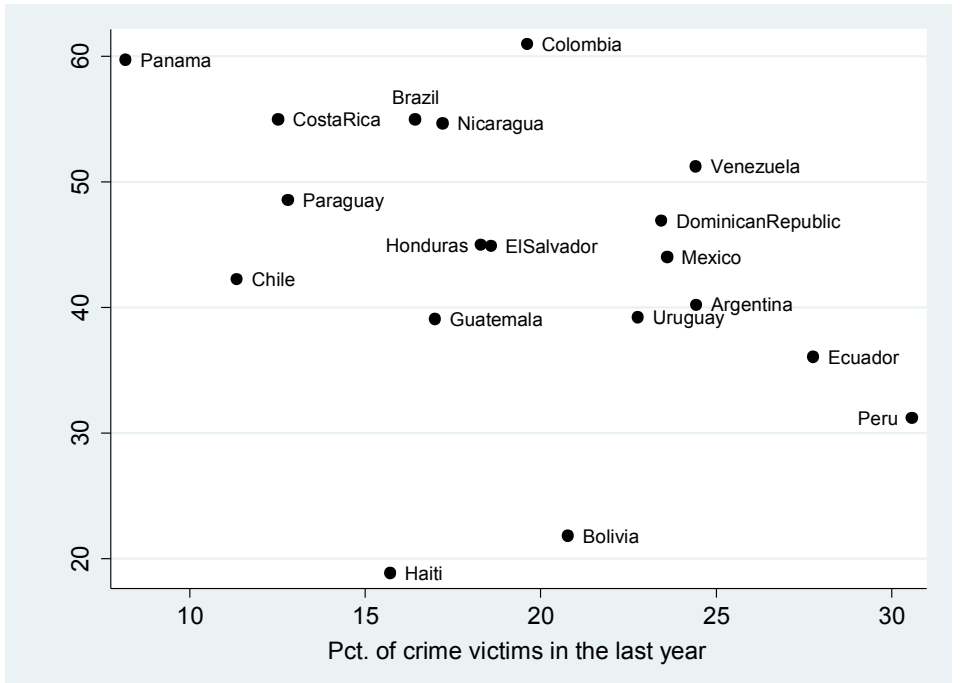

Source: Authors' calculations based on LAPOP 2014.

\section{METHODOLOGY}

The effect of victimization on individual life satisfaction is generally studied using an ordered probit or logit model due to the nature of the variable. These models were considered in the first stage of this analysis but were determined to be inappropriate for the data because they have an underlying assumption known as the parallel regressions assumption or proportional odds assumption. This assumption occurs when the coefficients that explain the odds that the dependent variable will take on any of the defined categories

\footnotetext{
${ }^{3}$ The question on the LAPOP 2014 states, "Now, changing the subject, have you been a victim of any type of crime in the past 12 months? That is, have you been a victim of robbery, burglary, assault, fraud, blackmail, extortion, violent threats or any other type of crime in the past 12 months?" (1) Yes (2) No (88) DK (98) DA
} 
are the same for every category. Therefore, the Brant Test was used to evaluate whether our data met this assumption, but as the hypothesis of equal coefficients was rejected (Brant, 1990 ), we had to rely on the generalized ordered logit as the most suitable model (Greene \& Hensher, 2010).

Thus, to estimate the effect of victimization on individual life satisfaction, the generalized ordered logit with partial constraints, also known as the partial proportional odds model, is introduced. Its results are interpreted based on the marginal effects of each variable change on the probability that an individual rates his level of life satisfaction to be "very high."

\section{a. Generalized Ordered Logit with Partial Constraints}

The generalized ordered logit is a multinomial response model derived from the ordered logit, but it does not assume proportional odds. Williams (2006) introduces, as an extension of Fu's (1999) work, a specification of the generalized ordered logit and its implementation in Stata ${ }^{(\mathrm{c})}$ software (gologit2).

This model is a good option because, even though the model removes the assumption previously stated, it still accounts for the ordered nature of the dependent variable. According to Williams (2006), it may be defined as in equation (1):

$$
P\left(Y_{i}>j\right)=g\left(X_{i} \beta_{j}\right)=\frac{\exp \left(\alpha_{j}+X_{i} \beta_{j}\right)}{1+\left\{\exp \left(\alpha_{j}+X_{i} \beta_{j}\right)\right\}}, j=1,2, \ldots, M-1
$$

where $Y_{i}$ is the dependent response variable that takes on $M$ ordered values, $X_{i}$ is a vector containing explanatory variables for each individual $i$ and $j$ is the subscript for the possible values of Y. Both $\alpha$ and $\beta$ are parameters to be estimated. From this model, the odds of Y taking on each $\mathrm{M}$ value are:

$$
\begin{gathered}
P\left(Y_{i}=1\right)=1-g\left(X_{i} \beta_{j}\right) \\
P\left(Y_{i}=j\right)=g\left(X_{i} \beta_{j-1}\right)-g\left(X_{i} \beta_{j}\right), j=2, \ldots, M-1 \\
P\left(Y_{i}=M\right)=g\left(X_{i} \beta_{M-1}\right)
\end{gathered}
$$

Note that the previous model can also be specified so that some variables meet the proportional odds assumption. That is, for some explanatory variables, the $\beta$ coefficient must vary for each possible outcome, but for other variables, it may be correctly restricted. Adding these restrictions reduces the number of parameters to be estimated and results in a more parsimonious model. In this case, the new specification is as presented in equation (5). 


$$
P\left(Y_{i}>j\right)=\frac{\exp \left(\alpha_{j}+X_{1 i} \beta_{1}+X_{2 i} \beta_{2 j}\right)}{1+\left\{\exp \left(\alpha_{j}+X_{1 i} \beta_{1}+X_{2 i} \beta_{2 j}\right)\right\}}, j=1,2, \ldots, M-1
$$

where $X_{1 i}$ is a vector of explanatory variables whose coefficients are restricted to be equal for each value of $Y$. Because $X_{2 i}$ includes the variables for which the constraint is not maintained, its associated parameters vary across all values of $Y$.

To determine the variables that hold for the proportional odds assumption, an iterative process that begins by estimating the model without restrictions is used. Because this model actually estimates $M-1$ binary logit models, for each iteration, a Wald test is used to verify whether the coefficients are statistically significant across regressions. If the statistic is not significant for at least one variable, it restricts the variable with the least significant value. The model is then estimated again including the new restriction, and it tests each iteration until the test is significant for all remaining variables.

This model is estimated using maximum likelihood. In this model, the parameters of interest are not the $\beta$ coefficients, but rather, how the probability of obtaining a specific value for $Y$ varies with changes in the explanatory variables, i.e., the marginal effects. Therefore, the effect will also depend on the values of the independent variables for which they are estimated.

\section{b. Specification}

To identify the effect of having been a victim of a crime in the last 12 months on the probability of declaring a certain level of life satisfaction, a generalized ordered logit with partial constraints is proposed. Reported life satisfaction is a coded version of the true level of life satisfaction that, for obvious reasons, is a latent variable (not observed). Thus, the observed variable is the declared level of life satisfaction that, as previously explained, is a categorical variable that takes the values 1 (very dissatisfied) through 4 (very satisfied).

The model is represented using the following equation:

$$
P\left(\text { Life Satisfaction }_{i}>j\right)=\frac{\exp \left(\alpha_{j}+\operatorname{Victim}_{i} \beta_{1}+X_{2 i} \beta_{2}+X_{3 i} \beta_{3 j}\right)}{1+\left\{\exp \left(\alpha_{j}+\operatorname{Victim}_{i} \beta_{1}+X_{2 i} \beta_{2}+X_{3 i} \beta_{3 j}\right)\right.},
$$

where Life Satisfaction is an ordered categorical variable that takes the values 1 to 4 , with 1 corresponding to the lowest level of satisfaction and 4 corresponding to the highest level of satisfaction for the $i$-th individual. $X_{2 \mathrm{i}}$ and $X_{3 \mathrm{i}}$ are vectors containing sociodemographic controls for each individual such as gender, age, years of education, employment status, 
ethnic group, number of children at home, family income, marital status, etc. We also include dummies that capture the specific characteristics of each territory for each country in the sample. The explanatory variable $\operatorname{Victim}_{i}$ is a dummy variable that takes the value 1 if the $i$-th individual was a victim of a crime, such as robbery, burglary, assault, fraud, blackmail, extortion, violent threats, among others, in the last 12 months.

\section{RESULTS}

As previously stated, we use the generalized ordered probit model programmed by Williams (2006). The autofit option at a $1 \%$ level was specified. This command sets the level of confidence at which the constraints previously mentioned are imposed. Finally, the model estimation left without constraints the following variables: age squared, unemployment, number of children, race (black and indigenous), perception of neighborhood safety (all), weekly attendance at non-religious meetings and country dummies for Argentina, Bolivia, Brazil, Chile, Dominican Republic, Guatemala, Mexico, Paraguay, Peru and Uruguay ${ }^{4}$.

Table 3 reports the marginal effects on the likelihood of declaring the highest level of life satisfaction with respect to the average individual ${ }^{5}$. The standard errors, obtained using the delta method $^{6}$, are also included. These are the marginal effects of change on each variable as evaluated for the average individual. However, these marginal effects have been extensively criticized because it is clear that the average individual does not exist, particularly if the sample contains men and women living in different countries. Even so, a preliminary analysis of these marginal effects offers good insight for understanding the role of the variables that are not of particular interest in this study.

\footnotetext{
${ }^{4}$ Although the estimation results are not presented due to space limitations, it is noted that the estimation consisted of 24,918 observations, the hypothesis of joint non-significance is rejected at a $99 \%$ level of confidence, and the Pseudo $\mathrm{R}^{2}$ is 0.0637 . The estimation was robust to account for possible heteroscedasticity caused, for instance, by correlation among country groups. (Wooldridge, 2010)

${ }^{5}$ The use marginal effect in this section refers to the effect of a change of a given variable on the probability of declaring the highest level of life satisfaction, i.e., P(Life Satisfaction=4).

${ }^{6}$ The Delta Method is used to obtain the asymptotic variance of the marginal effects as $\left[\nabla_{\beta} h(\widehat{\boldsymbol{\beta}})\right] \widehat{\boldsymbol{V}}\left[\nabla_{\beta} h(\widehat{\boldsymbol{\beta}})\right]^{\prime}$, where $\nabla_{\beta} h(\widehat{\boldsymbol{\beta}})$ is the gradient of the marginal effects with respect to $\widehat{\boldsymbol{\beta}}$ and $\widehat{\boldsymbol{V}}$ is the asymptotic variance of the estimate of $\widehat{\boldsymbol{\beta}}$ (Wooldridge, 2010).
} 
Table 3: Marginal effects on the probability of being at the highest level of life satisfaction

\begin{tabular}{|c|c|c|c|c|c|}
\hline Variable & $\begin{array}{c}\text { Marginal } \\
\text { Effect } \\
\end{array}$ & $\begin{array}{c}\text { Standard } \\
\text { Error } \\
\end{array}$ & Variable & $\begin{array}{c}\text { Marginal } \\
\text { Effect } \\
\end{array}$ & $\begin{array}{c}\text { Standard } \\
\text { Error } \\
\end{array}$ \\
\hline Victim & $-0.036 * * *$ & 0.008 & Drinking water & $0.016^{*}$ & 0.009 \\
\hline Woman & -0.001 & 0.006 & Neighborhood Safety & & \\
\hline Age & $-1.289 \mathrm{E}-3 * * *$ & $2.91 \mathrm{E}-04$ & Very unsafe & 0.003 & 0.011 \\
\hline Education, years & $0.007 * * *$ & 0.001 & Somewhat unsafe & -0.012 & 0.008 \\
\hline Marital Status & & & Somewhat safe & - & - \\
\hline Single & - & - & Very safe & $0.160 * * *$ & 0.01 \\
\hline Married & 0.006 & 0.008 & Argentina & $-0.228 * * *$ & 0.022 \\
\hline Divorced & $-0.056 * * *$ & 0.014 & Bolivia & $-0.396 * * *$ & 0.018 \\
\hline Widowed & $-0.040 * *$ & 0.017 & Brazil & $-0.038 *$ & 0.02 \\
\hline Family Income & & & Chile & $-0.201 * * *$ & 0.021 \\
\hline Low & - & - & Colombia & - & - \\
\hline Medium & $0.037 * * *$ & 0.008 & Costa Rica & -0.026 & 0.02 \\
\hline High & $0.103 * * *$ & 0.008 & Dominican Republic & $-0.099 * * *$ & 0.019 \\
\hline Unemployed & $-0.076 * * *$ & 0.015 & Ecuador & $-0.241 * * *$ & 0.019 \\
\hline Children, number & -0.001 & 0.002 & El Salvador & $-0.156^{* * *}$ & 0.019 \\
\hline Ethnic Group & & & Guatemala & $-0.202 * * *$ & 0.02 \\
\hline White & 0.011 & 0.008 & Haiti & $-0.457 * * *$ & 0.026 \\
\hline Black & -0.009 & 0.016 & Honduras & $-0.147 * * *$ & 0.018 \\
\hline Mestizo & - & - & México & $-0.148 * * *$ & 0.02 \\
\hline Mulatto & -0.006 & 0.015 & Nicaragua & $-0.058 * * *$ & 0.019 \\
\hline Indigenous & -0.013 & 0.012 & Panamá & -0.014 & 0.019 \\
\hline Other & -0.033 & 0.029 & Paraguay & $-0.111 * * *$ & 0.02 \\
\hline Attends weekly meetings & & & Peru & $-0.290 * * *$ & 0.021 \\
\hline Religious & $0.034 * * *$ & 0.007 & Uruguay & $-0.208 * * *$ & 0.02 \\
\hline Non-religious & $0.051 * * *$ & 0.012 & Venezuela & $-0.085 * * *$ & 0.02 \\
\hline Urban Area & 0.011 & 0.007 & & & \\
\hline
\end{tabular}

Marginal effect is the marginal effect of each variable on the probability of reporting the highest level of life satisfaction. Statistical significance is presented for the $1 \%(* * *), 5 \%(* *)$ and $10 \%(*)$ levels. Column St. Dev. corresponds to the standard deviations of the marginal effects as obtained using the delta method.

Source: Authors' calculations based on LAPOP 2014.

As inferred from Table 3, the main estimates are aligned with previous literature. One of the results that differs, however, is that neither the dummy variable for women nor its marginal effect on the odds of declaring the highest level of life satisfaction were found to be significant in the model. Additionally, the number of children does not have a statistically significant marginal effect, even though the obtained sign is, as expected, negative. Age is significant, and its marginal effect is negative such that one additional year, with respect to age, diminishes the probability of the individual reporting the highest 
level of life satisfaction. Moreover, this effect is not linear as there is a point where probability is minimized. Years of education was found to be significant and to have a positive marginal effect, although the effect was only 0.7 percentage points for each additional year. Being married was not found to have a significant effect on the odds of being very satisfied with life, a finding that is consistent with previous literature. However, the marginal effect of being divorced or widowed is negative and significant. Similarly, attending weekly non-religious or religious meetings increases the probability of reporting the highest level of life satisfaction by 3.4 and 5.1 percentage points, respectively. These findings support the hypothesis that being part of a social group positively influences one's level of happiness.

Moreover, marginal effects of income and unemployment variables are as expected. Being unemployed decreases the odds of being very satisfied with life by 7.6 percentage points. With respect to income, if a person reports having a high or medium income, i.e., in the top $33 \%$ or $66 \%$, respectively, of their country, their chances of being very satisfied with life are 3.7 and 10.3 percentage points higher, respectively, than individuals whose income is in the lowest $33 \%$.

Regarding household variables, living in an urban area has a positive but non-significant effect, whereas having drinking water available at home has a positive and significant effect at a $90 \%$ confidence level. A marginal effect of perception of neighborhood safety is only significant for the "very safe" dummy. This effect is positive compared to living in a "somewhat safe" neighborhood, with the likelihood of being very satisfied with life increasing by 16 percentage points. The findings regarding perception of neighborhood safety support those of other studies, such as that of Medina et al. (2012).

The observed signs for the marginal effects of the country controls are also notable. The omitted variable is Colombia, which means that living in any of the other 18 countries decreases the likelihood of being very satisfied with life in comparison to living in Colombia.

Finally, Figure 3 presents the marginal effects of having been a victim of a crime in the last 12 months on the individual's level of satisfaction with life. These effects are obtained for the average individual of each country ${ }^{7}$. The results suggest that being a victim of a crime in the past year effectively reduces the probability of the individual being very satisfied with life in all of the 19 countries that were analyzed (standard errors are shown in Table A.1. in the appendix). The lowest effect is observed for the average Haitian, whose likelihood of being very satisfied with life after being victimized is reduced by 1.4

\footnotetext{
${ }^{7}$ Marginal effects for the average woman and man from each country were considered for presentation. Eventually, these results were not presented because the variable gender was not statistically significant. This results in marginal effects for the average man and woman with negligible differences (from $0.08 \%$ to $0.35 \%)$.
} 
percentage points. However, higher effects are observed for individuals in Colombia, Panamá and Costa Rica, where the odds are reduced by 3.6 percentage points in Colombia and Panamá and by 3.5 percentage points in Costa Rica.

Figure 3. Marginal effect of victimization on each country's life satisfaction

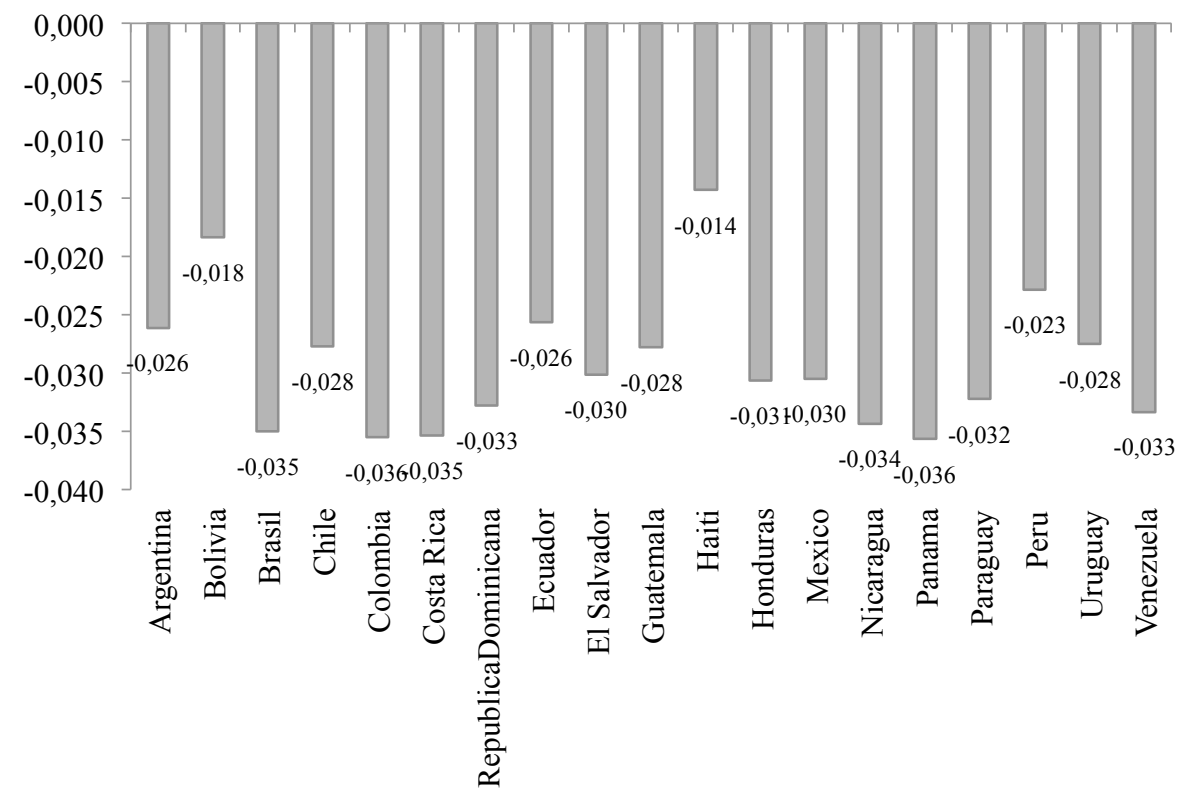

Source: Authors' calculations based on LAPOP 2014.

\section{CONCLUDING REMARKS}

The study of happiness is a growing field among economists and other disciplines due to its close relationship with quality of life at the individual level, and thus, it is also an indicator of the efficiency of policy makers. In this way, the development of this line of research is enriched by the findings of studies, such as that of Easterlin (1974, 2004). After several analyses, he finds that there is not a deterministic relationship between individual income and the reported level of satisfaction. Therefore, there is the need to identify and examine the material and non-material determinants of subjective happiness. Consistent with this line of reasoning, it has been found that safety and victimization could be among the determinants that directly impact life satisfaction at the individual level. Thus, the causal relationship between victimization and happiness becomes an empirical question.

Previous literature that has studied the relationship between victimization and life satisfaction has relied on ordered probit models. However, using data from the 2014 
LAPOP AmericasBarometer, we determine that the assumptions for those models to hold are not met, and therefore, we propose a generalized ordered logit model to solve the problems and estimate consistent parameters.

Our main estimates suggest that for the 19 Latin American countries, being a victim of a crime has a negative and significant effect on the probability of the victim reporting the highest level of life satisfaction. This effect ranges from -1.4 to -3.6 percentage points depending on each country's socioeconomic context. In Chile, the odds of the average citizen being very satisfied with life is reduced from $25.7 \%$ to $23 \%$, while in Haiti, the reduction is greater, decreasing from $11.2 \%$ prior to victimization to $9.8 \%$ after victimization. Similarly, these rates in Panamá are reduced from $41.8 \%$ to $38.2 \%$, and in Colombia, they are reduced from $60.1 \%$ to $56.5 \%$. The effects of being widowed or transitioning from low income to medium income are, in magnitude, comparable with those of being victimized, thus highlighting the importance of victimization.

Consistent with previous findings, crime does not only lead to monetary costs but also to costs with respect to social welfare. Accordingly, the individual must have been directly affected by a crime, i.e., the individual must have been victimized for the significance of the decrease in the reporting of the highest level of life satisfaction to be considered. Although this study finds related evidence, the finding regarding the impact of being a victim is verified by Cohen (2008), who finds that living in a territory with high rates of homicides and crime is not significant in terms of reducing the reported level of life satisfaction, whereas being directly affected by crime is significant.

The main findings with respect to the Colombian context are challenging because, even though after its 50 years of armed conflict with generalized violence on numerous fronts, including guerilla warfare, paramilitarism, drug trafficking, criminal gangs, rural and urban violence and even the recognition of Medellin in 1991 as the most violent city in the world, the country's population has ranked first in happiness since such measurements have been implemented. This situation is similar to that observed in Mexico.

In the Latin American context as a whole, a negative and significant effect is observed for individuals who were victimized in the previous year on the probability of those individuals declaring the highest level of life satisfaction. This is one of the reasons why public policy should pay special attention to reducing crimes such as robbery, burglary, physical assaults, extortion and other types of crime that directly affect individuals. Given that measurements of happiness are gradually being accepted as proxies for social progress, the study of happiness is driving policy makers to rethink their role regarding quality of life at the level of the individual. It must go beyond just designing policies focused on GDP growth and per capita income. It is also important to understand what makes citizens feel good on a day-today basis, and it must be realized that what makes them feel good is more than just GDP digits. Rather, it is what Easterlin explained in 1974 in the paradox he presented. 


\section{REFERENCES}

Ansa Eceiza, M. M. (2005). Economía y felicidad: Acerca de la relación entre bienestar material y bienestar subjetivo. XI Jornadas de economía critica.

Becchetti, L. (2011). Beyond the homo economicus. Working Paper No. 97, University of Rome Tor Vergata.

Becchetti, L., Bruni, L., \& Zamagni, S. (2015). Human Values, Civil Economy and Subjective Well-Being. En World Happiness Report (págs. 133-151).

Brant, R. (1990). Assessing Proportionality in the Proportional Odds Model for Ordinal Logistic Regression. Biometrics, 46(4), 1171-1178.

Cohen, M. A. (2008). The Effect of Crime on Life Satisfation. The Journal of Legal Studies, 37(S2), S325-S353.

Di Tella, R., \& MacCulloch, R. (2008). Gross national happiness as an answer to the Easterlin Paradox? Journal of Development Economics, 86(1), 22-42.

Di Tella, R., MacCulloch, R. J., \& Oswald, A. J. (2003). The Macroeconomics of Happiness. Review of Economics and Statistics, 85(4), 809-827.

Di Tella, R., MacCulloch, R., \& Ñopo, H. (2008). Happiness and Beliefs in Criminal Environments. IDB Working Paper.

Easterlin, R. A. (1974). Does Economic Growth Improve the Human Lot? Some Empirical Evidence. Nations and households in economic growth, 89, 89-125.

Easterlin, R. A. (2004). The Economics of Happiness. Daedalus, 133(2), 26-33.

Easterlin, R. A., Angelescu, L., \& Zweig, J. S. (2011). The Impact of Modern Economic Growth on Urban-Rural Differences in Subjective Well-Being. World Development, 39(12), 2187-2198.

Frey, B. S., \& Stutzer, A. (2002). What Can Economists Learn from Happiness Research? Journal of Economic Literature, 40(2), 402-435.

Fu, V. K. (1999). Estimating generalized ordered logit models. Stata Technical Bulletin, $8(44)$.

Greene, W. H., \& Hensher, D. A. (2010). Modeling Ordered Choices. New York, United States: Cambridge University Press.

Helliwell, J. F., Huang, H., \& Wang, S. (2015). The Geography of World Happiness. En World Happiness Report (págs. 12-41).

Kahneman, D., \& Krueger, A. B. (2006). Developments in the Measurement of Subjective Well-Being. Journal of Economic Perspectives, 24(3), 3-24. 
Medina, C., \& Tamayo, J. A. (2012). An Assessment of How Urban Crime and Victimization Affects Life Satisfaction. En Subjective Well-Being and Security (págs. 91-147). Springer Netherlands.

Ossandón, J. C. (2001). Felicidad y Política. El fin último de la polis en la filosofía de Aristóteles. Cuadernos de Anuario Filosófico(125), 101-150.

Powdthavee, N. (2005). Unhappiness and Crime: Evidence from South Africa. Economica, 72(287), 531-547.

Rojas, M. (2009). Economía de la felicidad: hallazgos relevantes respecto al ingreso y el bienestar. El trimestre económico, 537-573.

Staubli, S., Killias, M., \& Frey, B. S. (2014). Happiness and Victimization: An empirical study for Switzerland. European Journal of Criminology, 11(1), 57-72.

Switek, M. (2012). Life Satisfaction in Latin America: A Size-of-Place Analysis. The Journal of Development Studies, 48(7), 983-999.

Vanderbilt University. (28 de Febrero de 2016). Latin American Public Opinion Project. Obtenido de http://www.vanderbilt.edu/lapop/about.php

Williams, R. (2006). Generalized ordered logit/partial proportional odds models for ordinal dependent variables. Stata Journal, 6(1), 58-82.

Wills-Herrera, E., Orozco, L. E., Forero-Pineda, C., Pardo, O., \& Andonova, V. (2011). The relationship between perceptions of insecurity, social capital and subjective well-being. The Journal of Socio-Economics, 40(1), 88-96.

Wooldridge, J. M. (2010). Econometric Analysis of Cross Section and Panel Data. MIT Press.

Zechmeister, E. J. (2014). The political culture of democracy in the Americas, 2014: democratic governance across 10 years of the AmericasBarometer. AmericasBarometer Insights: 2014(108). 


\section{Appendix A.1}

Table A.1: Marginal effect of victimization in each country

\begin{tabular}{lcc|lcc}
\multicolumn{1}{c}{ Country } & $\begin{array}{c}\text { Marginal } \\
\text { Effect }\end{array}$ & $\begin{array}{c}\text { Standard } \\
\text { Deviation }\end{array}$ & Country & $\begin{array}{c}\text { Marginal } \\
\text { Effect }\end{array}$ & $\begin{array}{c}\text { Standard } \\
\text { Deviation }\end{array}$ \\
\hline \hline Argentina & $-0.026^{* * *}$ & 0.006 & Haiti & $-0.014^{* * *}$ & 0.003 \\
Bolivia & $-0.018^{* * *}$ & 0.004 & Honduras & $-0.031^{* * *}$ & 0.007 \\
Brazil & $-0.035^{* * *}$ & 0.008 & Mexico & $-0.030^{* * *}$ & 0.007 \\
Chile & $-0.028^{* * *}$ & 0.006 & Nicaragua & $-0.034^{* * *}$ & 0.008 \\
Colombia & $-0.036^{* * *}$ & 0.008 & Panama & $-0.036^{* * *}$ & 0.008 \\
Costa Rica & $-0.035^{* * *}$ & 0.008 & Paraguay & $-0.032^{* * *}$ & 0.007 \\
Dominican & $-0.033^{* * *}$ & 0.007 & Peru & $-0.023^{* * *}$ & 0.005 \\
Republic & $-0.026^{* * *}$ & 0.006 & Uruguay & $-0.028^{* * *}$ & 0.006 \\
Ecuador & $-0.030^{* * *}$ & 0.007 & Venezuela & $-0.033^{* * *}$ & 0.008 \\
El Salvador & $-0.028^{* * *}$ & 0.006 & & & \\
Guatemala & & & & \\
\hline
\end{tabular}

Column marginal effect is the marginal effect of the variable victim on the probability of being at the highest level of life satisfaction for the average individual of each country. Statistical significance is presented for the $1 \%(* * *), 5 \%(* *)$ and $10 \%(*)$ levels. Column St. Dev. corresponds to the standard deviations of the marginal effects as obtained by using the delta method.

Source: Authors' calculations based on LAPOP 2014. 